\title{
Full Scale Coated Fiber Neutron Detector Measurements
}

\author{
RT Kouzes \\ JH Ely \\ LE Erikson \\ WJ Kernan \\ DC Stromswold \\ ML Woodring
}

March 17, 2010

\section{Pacific Northwest}

NATIONAL LABORATORY

Proudly Operated by Battelle Since 1965 


\title{
DISCLAIMER
}

This report was prepared as an account of work sponsored by an agency of the United States Government. Neither the United States Government nor any agency thereof, nor Battelle Memorial Institute, nor any of their employees, makes any warranty, express or implied, or assumes any legal liability or responsibility for the accuracy, completeness, or usefulness of any information, apparatus, product, or process disclosed, or represents that its use would not infringe privately owned rights. Reference herein to any specific commercial product, process, or service by trade name, trademark, manufacturer, or otherwise does not necessarily constitute or imply its endorsement, recommendation, or favoring by the United States Government or any agency thereof, or Battelle Memorial Institute. The views and opinions of authors expressed herein do not necessarily state or reflect those of the United States Government or any agency thereof.

\author{
PACIFIC NORTHWEST NATIONAL LABORATORY \\ operated by \\ BATTELLE \\ for the \\ UNITED STATES DEPARTMENT OF ENERGY \\ under Contract DE-AC05-76RL01830
}

Printed in the United States of America

Available to DOE and DOE contractors from the

Office of Scientific and Technical Information,

P.O. Box 62, Oak Ridge, TN 37831-0062;

ph: (865) 576-8401

fax: (865) 576-5728

email: reports@adonis.osti.gov

Available to the public from the National Technical Information Service,

U.S. Department of Commerce, 5285 Port Royal Rd., Springfield, VA 22161

ph: (800) 553-6847

fax: (703) 605-6900

email: orders@ntis.fedworld.gov

online ordering: http://www.ntis.gov/ordering.htm

ACKNOWLEDGEMENT

This work was supported by the National Nuclear Security Administration, Office of Nonproliferation Research and Development (NA-22) 
PNNL-19264

\title{
Full Scale Coated Fiber Neutron Detector Measurements
}

\author{
RT Kouzes \\ JH Ely \\ LE Erikson \\ WJ Kernan \\ DC Stromswold \\ ML Woodring
}

March 17, 2010

Pacific Northwest National Laboratory

Richland, Washington 99352 


\section{Executive Summary}

Radiation portal monitors used for interdiction of illicit materials at borders include highly sensitive neutron detection systems. The main reason for having neutron detection capability is to detect fission neutrons from plutonium. The currently deployed radiation portal monitors (RPMs) from Ludlum and Science Applications International Corporation (SAIC) use neutron detectors based upon ${ }^{3} \mathrm{He}$-filled gas proportional counters, which are the most common large neutron detector. There is a declining supply of ${ }^{3} \mathrm{He}$ in the world, and thus, methods to reduce the use of this gas in RPMs with minimal changes to the current system designs and sensitivity to cargo-borne neutrons are being investigated.

Four technologies have been identified as being currently commercially available, potential alternative neutron detectors to replace the use of ${ }^{3} \mathrm{He}$ in RPMs. These technologies are:

1) Boron trifluoride $\left(\mathrm{BF}_{3}\right)$-filled proportional counters,

2) Boron-lined proportional counters,

3) Lithium-loaded glass fibers, and

4) Coated non-scintillating plastic fibers.

Reported here are the results of tests of the full-scale ${ }^{6} \mathrm{Li} / \mathrm{ZnS}(\mathrm{Ag})$-coated non-scintillating plastic fibers option. This testing measured the required performance for neutron detection efficiency and gamma ray rejection capabilities of a system manufactured by Innovative American Technology (IAT) and Saint Gobain, and is a follow-up report to an earlier one on a smaller prototype system.

Results indicate that the full-scale IAT system tested fell short of the neutron detection efficiency requirement due to a manufacturing problem. Innovative American Technology, working with Saint Gobain, is taking corrective action to deliver a system that exceeds this requirement. It was found that the system had adequate gamma ray rejection capability and a GARRn value within the acceptable range at reduced neutron efficiency when an appropriate threshold was used.

Testing of an enhanced paddle did not show the expected improvement in performance. However, tests on a new design of the detector with moderator inserted between layers showed a significant improvement in efficiency while meeting the gamma ray insensitivity requirement. If this design is scaled up to the full sized neutron detection system, the performance should meet the requirements for neutron sensitivity and gamma ray rejection. 


\section{Acronyms and Abbreviations}

ANSI

cps

DOE

GARRn

IAT

PNNL

PolyBox

PVT

RPM

RSP

SAIC

RPM

RSP

SAIC
American National Standards Institute

counts per second

U.S. Department of Energy

Gamma Absolute Rejection Ratio in the presence of neutrons

Innovative American Technologies

Pacific Northwest National Laboratory

polyethylene moderator/reflector box

Polyvinyl Toluene (plastic) scintillation gamma detector

Radiation Portal Monitor

Radiation Sensor Panel

Science Applications International Corporation

Radiation Portal Monitor

Radiation Sensor Panel

Science Applications International Corporation 


\section{Contents}

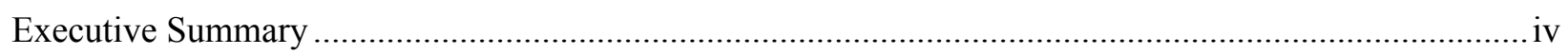

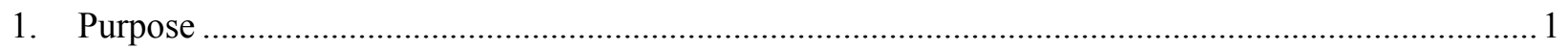

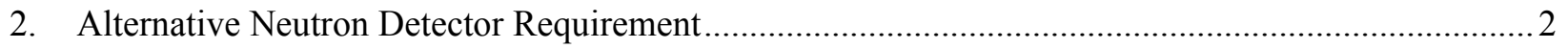

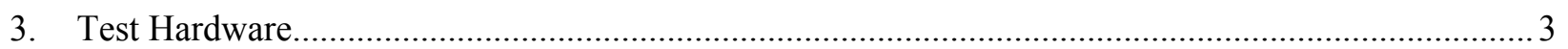

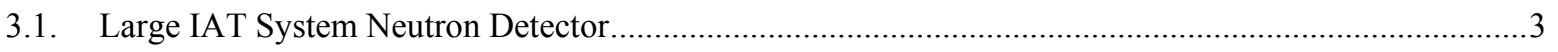

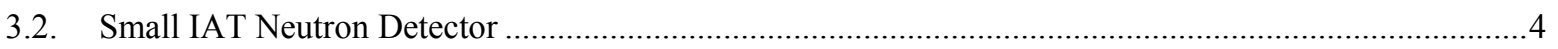

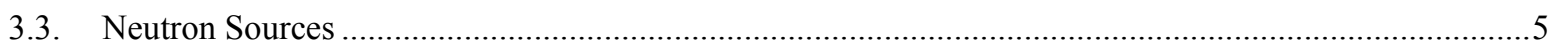

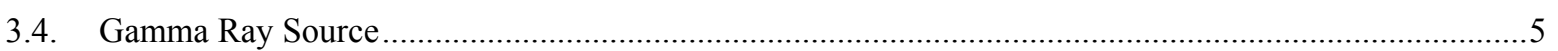

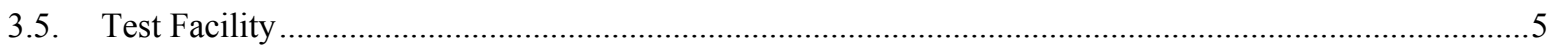

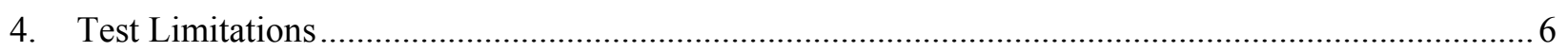

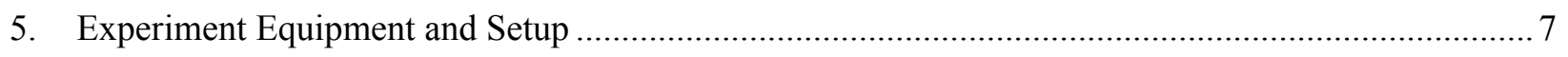

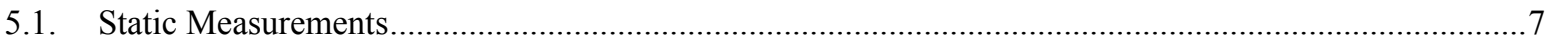

5.2. Gamma Insensitivity Measurements Of Large IAT System..................................................................

5.3. Gamma Insensitivity Measurements Of Small IAT System ...............................................................

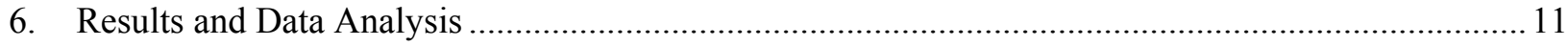

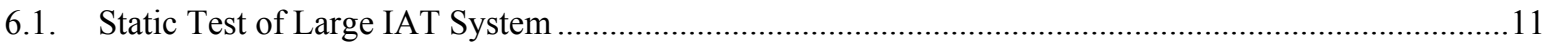

6.2. Static Test Of Enhanced Paddle For Large IAT System ...................................................................12

6.3. Gamma Insensitivity Test Of The Large IAT System ............................................................................14

6.4. Gamma Insensitivity Test Of The Upgraded Small IAT System .........................................................17

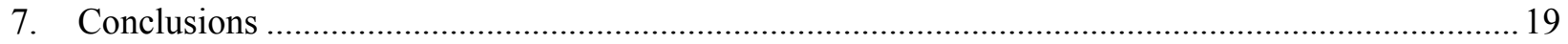

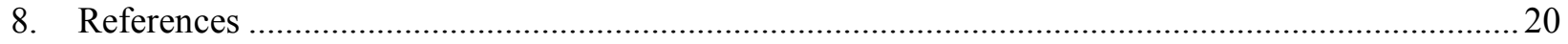




\section{Figures and Tables}

\section{Figures}

Figure 3.1: Internal view of showing half of the full-scale IAT detector and electronics......................... 3

Figure 3.2: Internal view of the upgraded small IAT detector.............................................................. 4

Figure 5.1: IAT detector positioned for static measurements. ............................................................. 7

Figure 5.2: IAT detector positioned for static measurements with added polyethylene reflector. .............. 8

Figure 5.3: Small IAT detector positioned for gamma ray and neutron measurements. ........................... 10

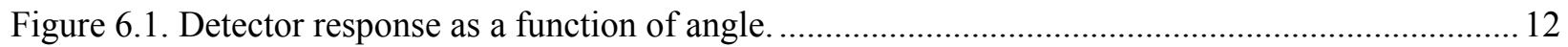

Figure 6.2. New and old paddles in a moderator box for testing. .......................................................... 13

Figure 6.3. Response of new (Det 1) and old (Det 2) paddles to a neutron source.................................. 13

Figure 6.4: Pulse height spectra of the four individual detectors with only the neutron source. ............... 14

Figure 6.5: Pulse height spectra of the four individual detectors with the neutron source and at a gamma

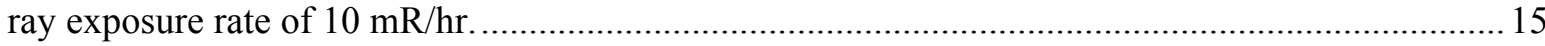

Figure 6.6: Pulse height spectra from the two detector paddles in the small IAT system in response to

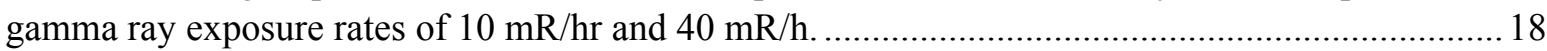

\section{Tables}

Table 5.2: Exposure rate versus distance for the ${ }^{60} \mathrm{Co}$ source............................................................... 9

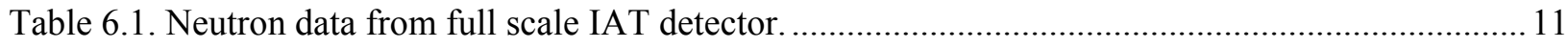

Table 6.2: "Neutron" counts recorded for various ${ }^{60} \mathrm{Co}$ exposure rates with a zero threshold. ................. 15

Table 6.3: "Neutron" counts recorded for various ${ }^{60} \mathrm{Co}$ exposure rates with a threshold at channel $43 \ldots . . .16$

Table 6.4: Estimates of absolute efficiency, GARRn and the intrinsic gamma ray rejection factor for the different gamma exposure rates for the large detector tested for two thresholds (T)...................... 17 


\section{Purpose}

Radiation portal monitor (RPM) systems used for interdiction of illicit materials at borders include highly sensitive neutron detection systems (Kouzes et al. 2008). The main reason for having neutron detection capability is to detect fission neutrons from plutonium. The currently deployed radiation portal monitors from Ludlum and Science Applications International Corporation (SAIC) use neutron detectors based upon ${ }^{3} \mathrm{He}$-filled gas proportional counters, which are the most common large neutron detector.

Within the last few years, the amount of ${ }^{3} \mathrm{He}$ available for use in gas proportional counter neutron detectors has become more restricted, while the demand has significantly increased, especially for homeland security applications (Kouzes 2009). In the near future, limited supply is expected to curtail the use of ${ }^{3} \mathrm{He}$; therefore, alternative neutron detection technologies are being investigated for use in the radiation portal monitor systems being deployed for border security applications (Van Ginhoven 2009).

From a survey of technologies, only four technologies have been identified as currently commercially available, potential alternative neutron detectors to replace the use of ${ }^{3} \mathrm{He}$ in RPMs in the near-term. These technologies are:

1) Boron trifluoride $\left(\mathrm{BF}_{3}\right)$-filled proportional counters (from Reuter Stokes or LND),

2) Boron-lined proportional counters (from Reuter Stokes or LND),

3) Lithium-loaded glass fibers (from NucSafe), and

4) Coated non-scintillating plastic fibers (from Innovative American Technology [IAT]).

Reported here are the results of tests of: 1) the full-scale ${ }^{6} \mathrm{Li} / \mathrm{ZnS}(\mathrm{Ag})$-coated non-scintillating plastic fibers option, 2) an enhanced paddle from the full scale system, and 3) an upgraded version of the smaller IAT system.

This testing measured the required performance for neutron detection efficiency and gamma ray rejection capabilities of a system manufactured by Innovative American Technology (IAT) containing detectors from Saint Gobain, and is a follow-up report to an earlier one on a smaller prototype system (Lintereur et al., 2009).

The measurements made as part of this testing included:

1) Response of the system to moderated neutrons with the original detector moderator configuration

2) Response of the system to moderated neutrons with additional amounts of detector moderation

3) Response of the system to a high gamma-ray exposure rate to measure gamma sensitivity and the Gamma Ray Absolute Rejection Ratio, GARRn (Kouzes et al. 2009) 


\section{Alternative Neutron Detector Requirement}

Coated non-scintillating plastic fibers are a possible neutron detector replacement technology for ${ }^{3} \mathrm{He}-$ filled tubes. These fibers can be fashioned in dimensions that will fit in the space available in the currently deployed standard ${ }^{3}$ He-based RPM polyethylene box $[0.127 \mathrm{~m}$ deep x $0.304 \mathrm{~m}$ wide x $2.18 \mathrm{~m}$ tall (5 in. $\times 12$ in. $\times 85.7$ in.)] that contains the ${ }^{3} \mathrm{He}$ tubes. Previous measurements on an IAT plastic fiber detector with an active detection area of $0.25 \mathrm{~m}$ x $0.25 \mathrm{~m}$ (10" x 10 ") have been reported (Lintereur 2009).

Pacific Northwest National Laboratory (PNNL) has now tested a larger, full-scale IAT neutron detection system. A system for replacement of the current neutron detectors in a standard ${ }^{3} \mathrm{He}$-based RPM must fit within the space occupied by the present ${ }^{3} \mathrm{He}$-based neutron detection system, and this IAT system was designed to be such a replacement.

The standard ${ }^{3} \mathrm{He}$-based systems were purchased under a specification (Stromswold et al., 2003) that requires a single radiation sensor panel (RSP) to meet the following requirements:

"A ${ }^{252} \mathrm{Cf}$ neutron source will be used for testing neutron sensor sensitivity:

- To reduce the gamma-ray flux, the source shall be surrounded by at least $0.5 \mathrm{~cm}$ of lead. To moderate the neutron spectrum, $2.5 \mathrm{~cm}$ of polyethylene shall be placed around the source.

- The absolute detection efficiency for such $\mathrm{a}^{252} \mathrm{Cf}$ source, located $2 \mathrm{~m}$ perpendicular to the geometric midpoint of the neutron sensor, shall be greater than $2.5 \mathrm{cps} / \mathrm{ng}$ of ${ }^{252} \mathrm{Cf}$. The neutron detector center shall be $1.5 \mathrm{~m}$ above grade for this test. (Note: 10 nanograms of ${ }^{252} \mathrm{Cf}$ is equivalent to 5.4 micro-Ci or $2.1 \times 10^{4} \mathrm{n} / \mathrm{s}$, ${ }^{1}$ since ${ }^{252} \mathrm{Cf}$ has a $3.092 \%$ spontaneous fission (SF) branch and 3.757 neutrons/SF.)

- The neutron detector shall not generate alarms due to the presence of strong gamma-ray sources. The ratio of neutron sensor gamma-ray detection efficiency to neutron detection shall be less than 0.001."

To evaluate the performance of alternate neutron detectors compared to what is currently deployed three criteria are considered: 1) absolute neutron detection efficiency, 2) intrinsic efficiency of gamma rays detected as neutrons, and 3) GARRn.

The absolute neutron detection efficiency $\left(\epsilon_{\mathrm{abs} n}\right)$ required is that previously specified $(2.5 \mathrm{cps} / \mathrm{ng}$ from $\mathrm{a}{ }^{252} \mathrm{Cf}$ source at $2 \mathrm{~m}$ in a specified pig). The intrinsic efficiency of gamma rays detected as neutrons $\left(\epsilon_{\text {int } \gamma \mathrm{n}}\right)$ is the number of events that are counted as neutrons in the presence of a gamma source divided by the number of photons hitting the detector area, and shall be less than $10^{-6}$ at an exposure rate of 10 $\mathrm{mR} / \mathrm{h}$. The GARRn value is the number of events that are counted as neutrons $\left(\epsilon_{\mathrm{abs}} \mathrm{n}\right)$ in the presence of both a gamma and neutron source divided by the number of neutrons recorded without the gamma source $\left(\epsilon_{\mathrm{abs} n}\right)$, the requirement for this parameter is that $0.9 \leq \mathrm{GARRn} \leq 1.1$ at a $10 \mathrm{mR} / \mathrm{h}$ gamma exposure rate (Kouzes et al. 2009).

In addition, these systems are required to meet all aspects of the ANSI N42.35 standard (ANSI 2004). A summary of neutron detection systems in RPMs can be found in a PNNL report (Kouzes et al. 2007).

${ }^{1} 2.3 \times 10^{4} \mathrm{n} / \mathrm{s}$ is the currently used best known value 


\section{Test Hardware}

\subsection{Large IAT System Neutron Detector}

The IAT neutron detector uses non-scintillating plastic fibers (BC-704 from Saint Gobain) that are coated with ${ }^{6} \mathrm{Li} / \mathrm{ZnS}(\mathrm{Ag})$. The fibers are arranged side-by-side and the detector has four layers of fibers. The detector tested consists of four "paddles," each of which is $0.127 \mathrm{~m}$ by $0.635 \mathrm{~m}(5$ " x 25") with one phototube at the end. These paddles are mounted in a polyethylene box with $28.6 \mathrm{~mm}$ (1.125") walls on all sides. Figure 3.1 shows two of the paddles and the photomultiplier tubes in the polyethylene moderator box.

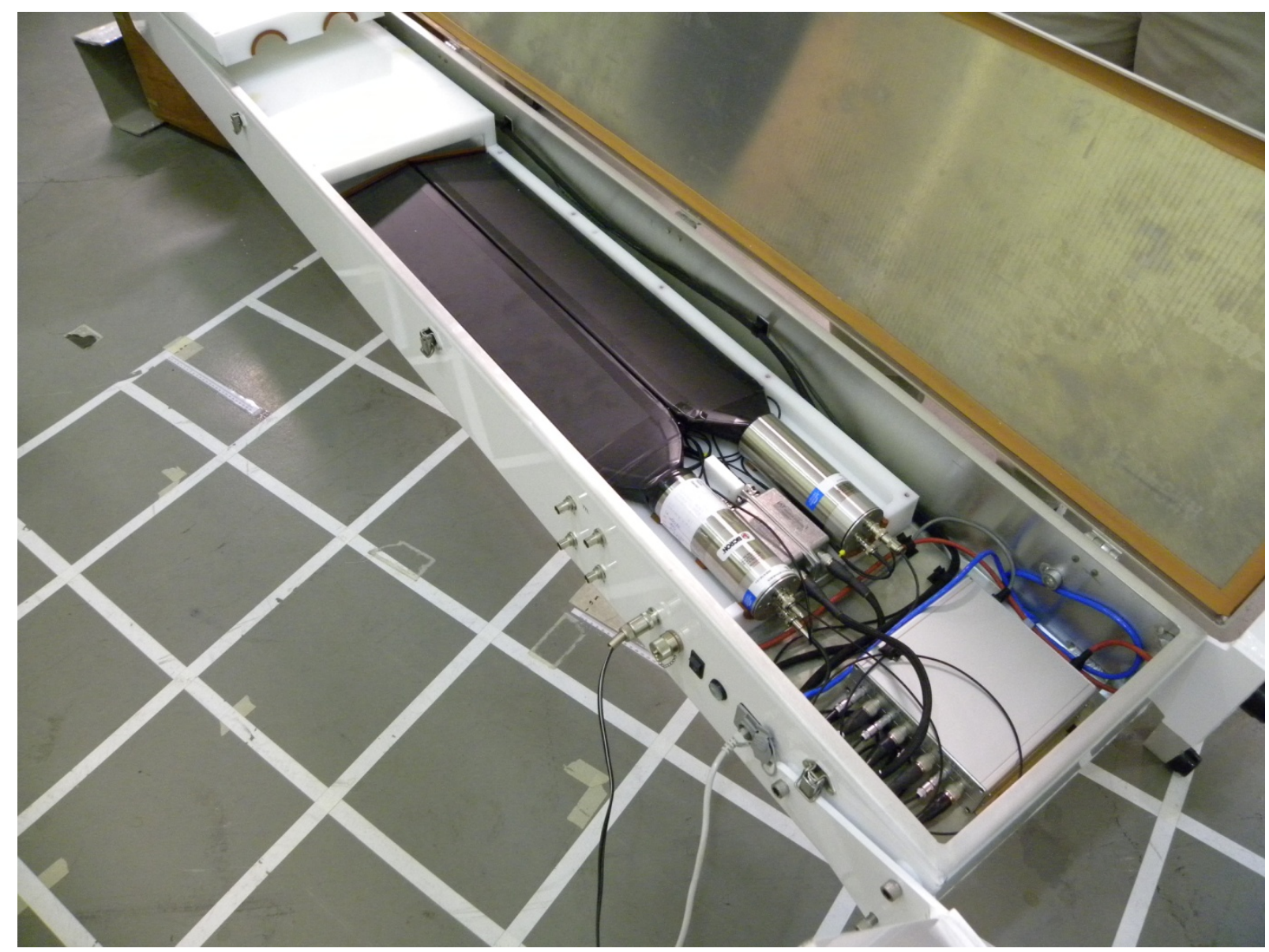

Figure 3.1: Internal view of showing half of the full-scale IAT detector and electronics.

The ${ }^{6} \mathrm{Li} / \mathrm{ZnS}(\mathrm{Ag})$ serves as a neutron absorber and phosphor. Thermal neutrons interact with the ${ }^{6} \mathrm{Li}$ resulting in the ${ }^{6} \mathrm{Li}(\mathrm{n}, \alpha)^{3} \mathrm{H}$ reaction, and the resultant charged particles produce light in the zinc sulfide. The plastic wavelength shifting fibers conduct the light to the photomultiplier tubes.

The electronics for the detector (lower right in Figure 3.1) process the signals to provide the neutron count rate. Signals from the photomultiplier tubes are digitized, and pulse-shape analysis yields discrimination between neutron and gamma ray pulses. Gamma ray pulses are narrower than neutron 
pulses (neutron pulses have a longer fall time) and have a faster rise time as calculated by averaging over several channels at the beginning of individual pulses.

Data are communicated over Ethernet to the data acquisition computer. Counts identified as "neutrons" are converted to count rate. Pulses identified as "gamma rays" are discarded and not tabulated in the present software.

\subsection{Small IAT Neutron Detector}

The small IAT neutron detector was first tested in August 2009 [Lintereur et al. 2009]. An upgraded version of this detector was delivered for testing in February 2010. It contains non-scintillating plastic fibers (BC-704 from Saint Gobain) that are coated with ${ }^{6} \mathrm{Li} / \mathrm{ZnS}(\mathrm{Ag})$. The fibers are arranged side-byside and the detector has four layers of fibers. The active width (coated) of the fiber array is $0.25 \mathrm{~m}$ and the active length is $0.25 \mathrm{~m}$. Fibers extend beyond the $0.25 \mathrm{~m}$ active length and are bundled at both ends into 0.05 -m-diameter photomultiplier tubes. The upgraded version of the system added a moderator between the layers of fibers. Figure 3.1 shows the (black) fiber array covered by the polyethylene moderator and the photomultiplier tubes.

On one side of the fiber array the $0.25 \mathrm{~m} \times 0.25 \mathrm{~m}$ polyethylene is $51 \mathrm{~mm}$ (2-inch) thick and on the other side it is $25 \mathrm{~mm}$ (1.0-inch) thick. Separate tests were conducted with a neutron source facing each of the polyethylene sides. The system is seen in Figure 3.2.

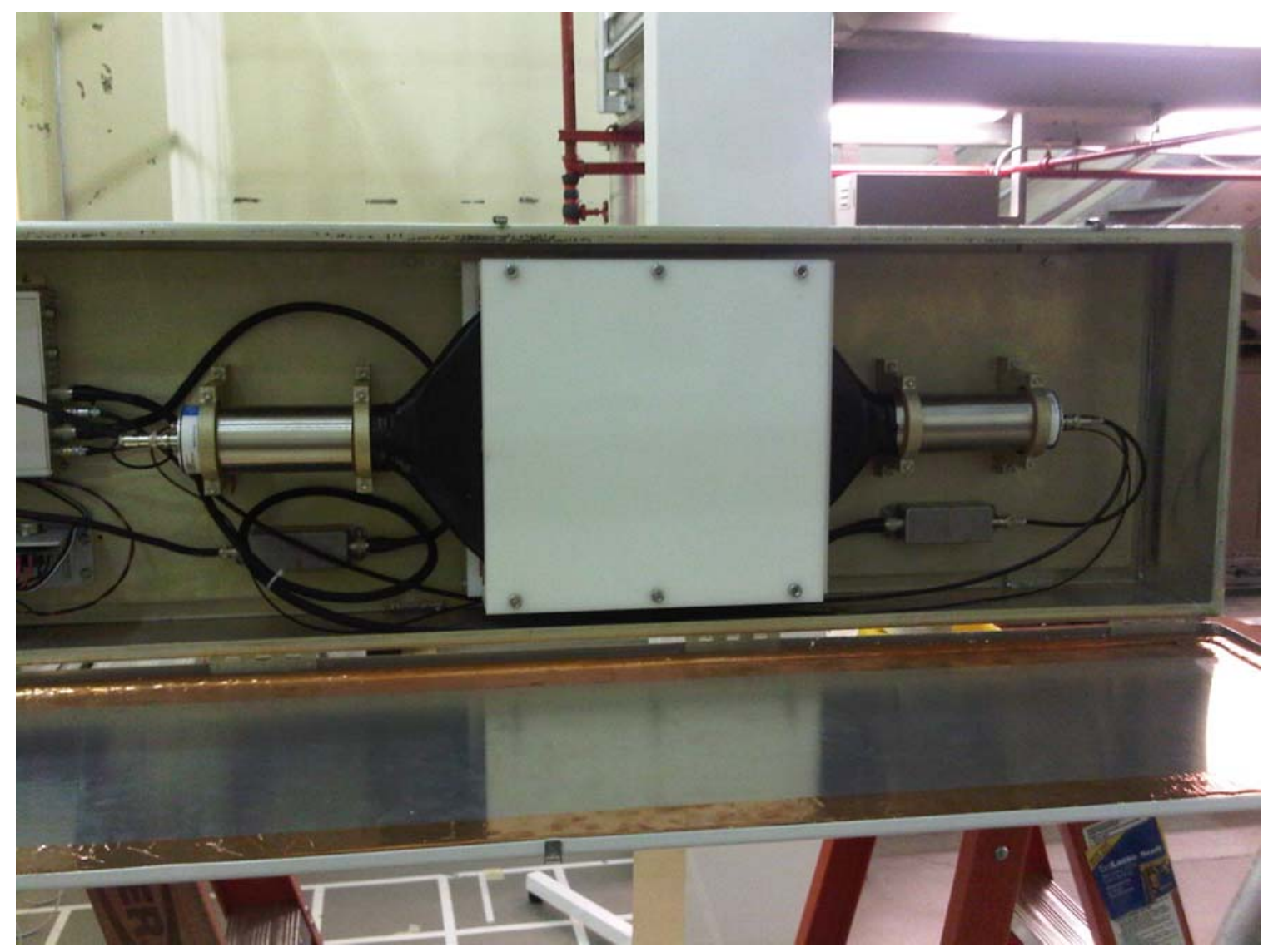

Figure 3.2: Internal view of the upgraded small IAT detector. 


\subsection{Neutron Sources}

The neutron source used for this test was ${ }^{252} \mathrm{Cf}$. The source was purchased from Isotope Products Laboratory (IPL) and given a PNNL ID of 60208-44. The source was measured by IPL to be $21.91 \pm$ $1.25 \mu \mathrm{Ci}$ on October 1,2009 . The source used was estimated to be $20.7 \mu \mathrm{Ci}$ on the date of the staticmeasurement tests (December 18, 2009). This activity corresponds to $38.4 \mathrm{ng}$ and an emanation rate of $8.8 \times 10^{4} \mathrm{n} / \mathrm{s}$ with the conversion factor stated in Section 2 .

This same neutron source was used in the tests conducted on January 12, 2010, when the gamma sensitivity of the detector was being tested. On this date the estimated source strength was $20.4 \mu \mathrm{Ci}$, with an activity corresponding to $37.7 \mathrm{ng}$ and emanation rate of $8.7 \times 10^{4} \mathrm{n} / \mathrm{s}$.

This same neutron source was also used in the tests conducted on February 23-24, 2010, when the gamma sensitivity of the improved detector was being tested. On this date the estimated source strength was $19.8 \mu \mathrm{Ci}$, with an activity corresponding to $36.6 \mathrm{ng}$ and emanation rate of $8.4 \times 10^{4} \mathrm{n} / \mathrm{s}$.

\subsection{Gamma Ray Source}

$\mathrm{A}{ }^{60} \mathrm{Co}$ source was used for the gamma sensitivity tests. The exact gamma ray source activity for these measurements was not known, and as the measurements were made indoors, scatter was assumed to be a larger contributing factor to any source strength measurement and calculation. The staff at Building 318 measured the exposure rate at a distance of $1.0 \mathrm{~m}$ from the source to be $144.1 \mathrm{mR} / \mathrm{h}$, which gave a source activity of $0.111 \mathrm{Ci}$ for the day of the testing.

\subsection{Test Facility}

The tests were performed at PNNL at the $331 \mathrm{G}$ Integration Test Facility and the 318 Radiological Calibrations Laboratory located in Richland, WA. The static tests were performed at $331 \mathrm{G}$ on Friday, December 18, 2009. The ${ }^{60}$ Co gamma insensitivity measurements were performed at Building 318 on January 12, 2010, and on February 23-24, 2010. 


\section{Test Limitations}

There were several limitations for this test and results may change with different conditions.

- Only one test location for each of the measurements was used, with the corresponding background. Since the testing was focused on net results (background subtracted) this should have little effect on the overall results.

- Only one IAT detector system was tested. Results may change with different detector geometries.

- Uncertainty in the neutron source strength was the main limitation to the test results. 


\section{Experiment Equipment and Setup}

\subsection{Static Measurements}

The neutron source was located on a tripod $2 \mathrm{~m}$ from the front or back face of the detector housing at a height that positioned the source in the center of the detector $(1.14 \mathrm{~m})$. Figure 5.1 shows the detector positioned for measurements.

Data were acquired for 10-minute time intervals. The source was located in a polyethylene pig (6 mm of lead and $25 \mathrm{~mm}$ of polyethylene). Measurements were taken perpendicular to the front and to the back at $2 \mathrm{~m}$, and at angles of 30,60 and 90 degrees from the front of the panel, also at $2 \mathrm{~m}$ from the panel front center.

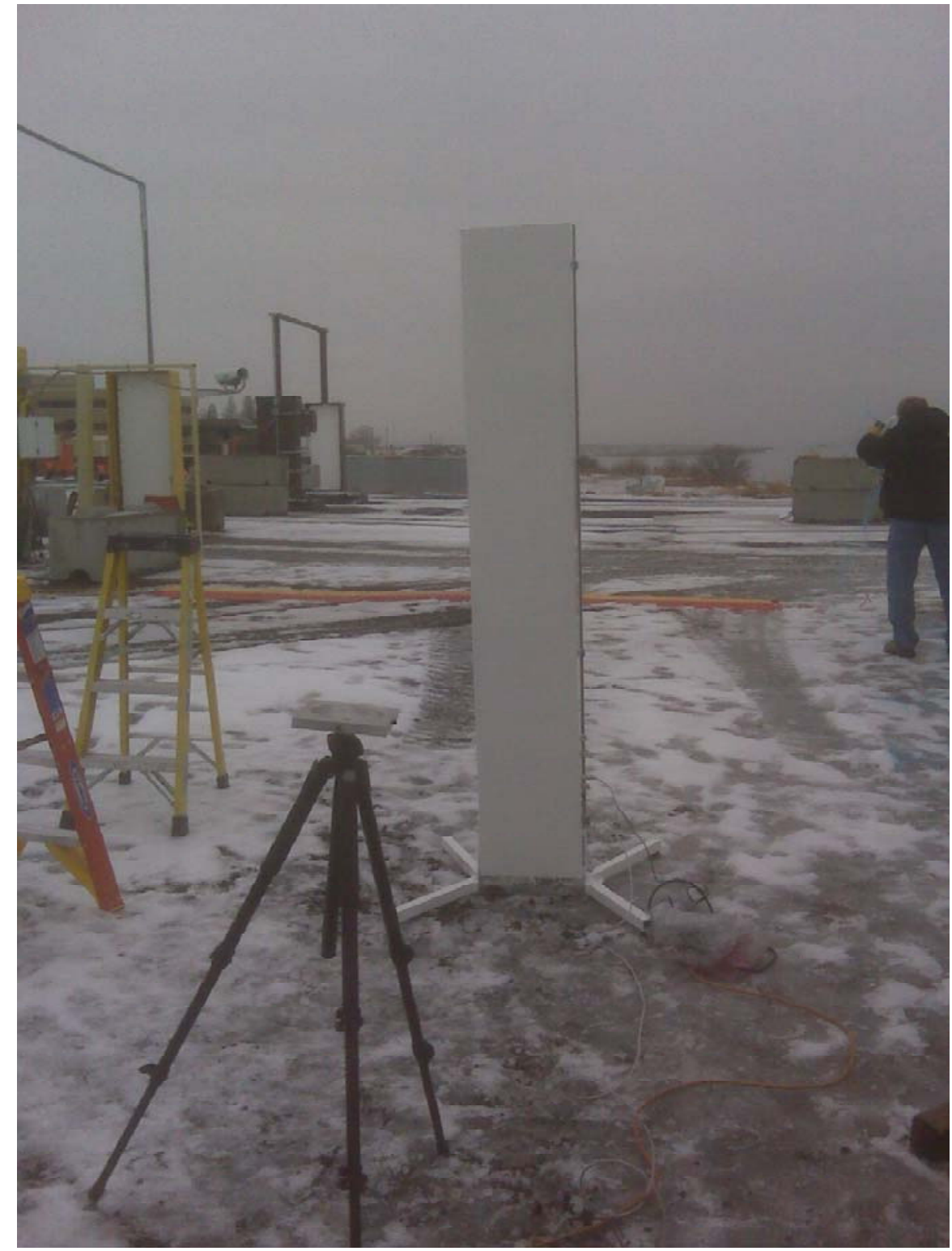

Figure 5.1: IAT detector positioned for static measurements. 
The original moderator arrangement was $28.6 \mathrm{~mm}$ (1.125") of polyethylene on all sides.

Measurements were also taken at $2 \mathrm{~m}$ from the front and the back of the detector with an added $38 \mathrm{~mm}$ (1.5") of polyethylene on the back surface as an added reflector. Figure 5.2 shows the detector with the added polyethylene reflector.

The static measurements were used to obtain data that allowed the IAT detector efficiency to be compared to the efficiency of the ${ }^{3} \mathrm{He}$ tube detector system used in the current SAIC systems.

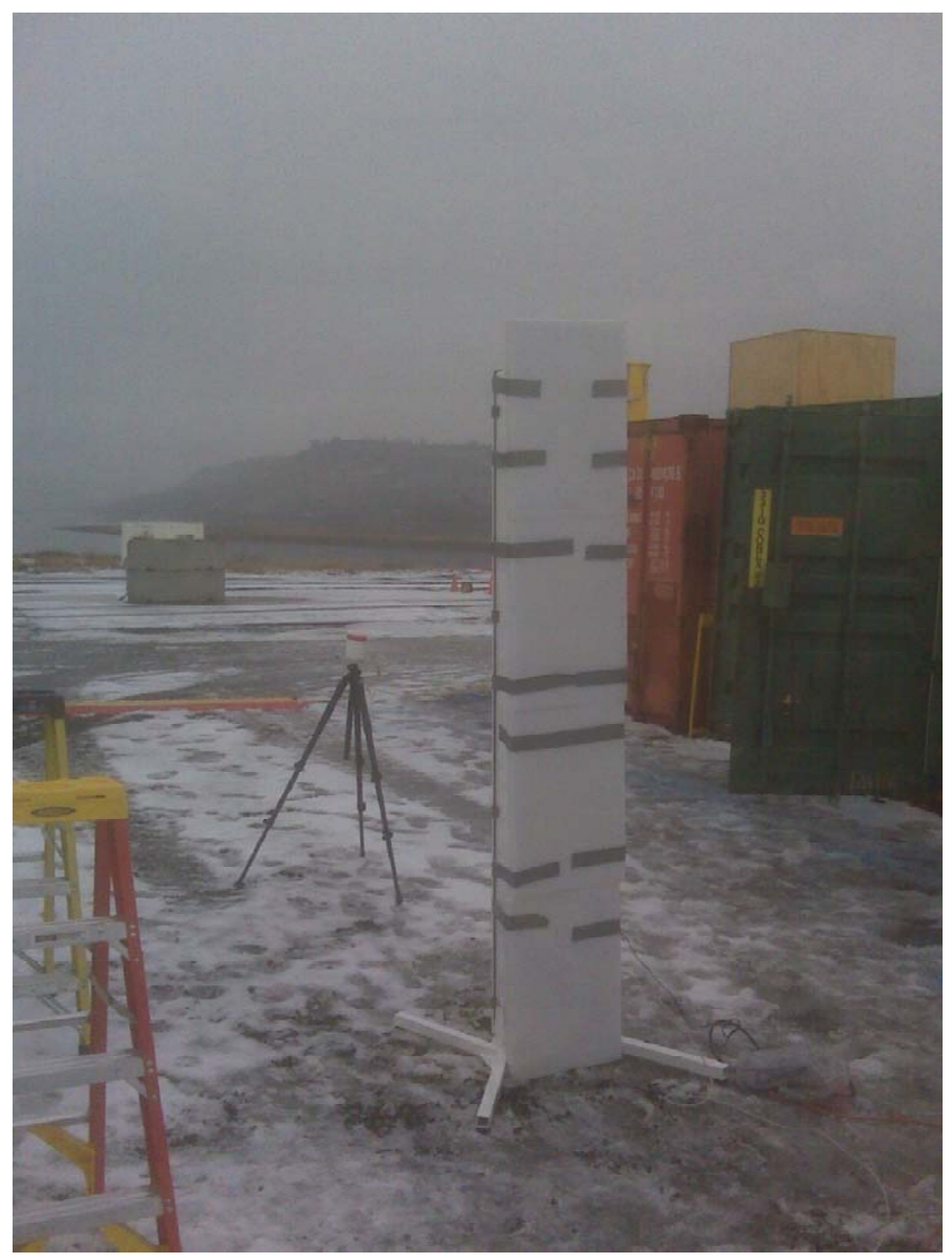

Figure 5.2: IAT detector positioned for static measurements with added polyethylene reflector. 


\subsection{Gamma Insensitivity Measurements Of Large IAT System}

The detector's sensitivity to gamma rays was tested with a high-activity ${ }^{60} \mathrm{Co}$ source used to flood the entire detector system with a high gamma exposure rate field.

The ${ }^{60} \mathrm{Co}$ gamma-sensitivity measurements were made with the front of the detector facing the gamma source.

The detector was moved to different distances from the source to obtain the desired exposure rates, as shown in Table 5.2, on the detector's front face when the source was in position. The distances required to achieve the exposure rates used for these measurements were determined by the source owners. Five-minute measurements were made for two different scenarios at each position:

1. ${ }^{60}$ Co source in place

2. ${ }^{60} \mathrm{Co}$ source and the neutron source, which was located on a tripod $2 \mathrm{~m}$ in front of or behind the detector.

Background measurements were made at the start, middle, and end of the data collection period.

Measurements with only the ${ }^{252} \mathrm{Cf}$ source $2 \mathrm{~m}$ from the front and back of the detector were also made at the $10 \mathrm{mR} / \mathrm{h}$ detector position with the gamma ray source closed.

Table 5.1: Exposure rate versus distance for the ${ }^{60} \mathrm{Co}$ source.

\begin{tabular}{|c|c|}
\hline Exposure Rate (mR/h) & Distance (m) \\
\hline 5 & 5.37 \\
\hline 10 & 3.80 \\
\hline 20 & 2.68 \\
\hline 40 & 1.90 \\
\hline 60 & 1.55 \\
\hline 80 & 1.34 \\
\hline 100 & 1.20 \\
\hline
\end{tabular}

\subsection{Gamma Insensitivity Measurements Of Small IAT System}

The upgraded small IAT system was also tested for gamma ray sensitivity in the same manner as the large system. Measurements were performed in a manner similar to those on the large system. Figure 5.3 shows the small system (with the yellow square on its front) supported horizontally on ladders while performing a neutron efficiency test (neutron source on the tripod) in the gamma ray test facility (gamma ray source is introduced into the tube in the foreground). 


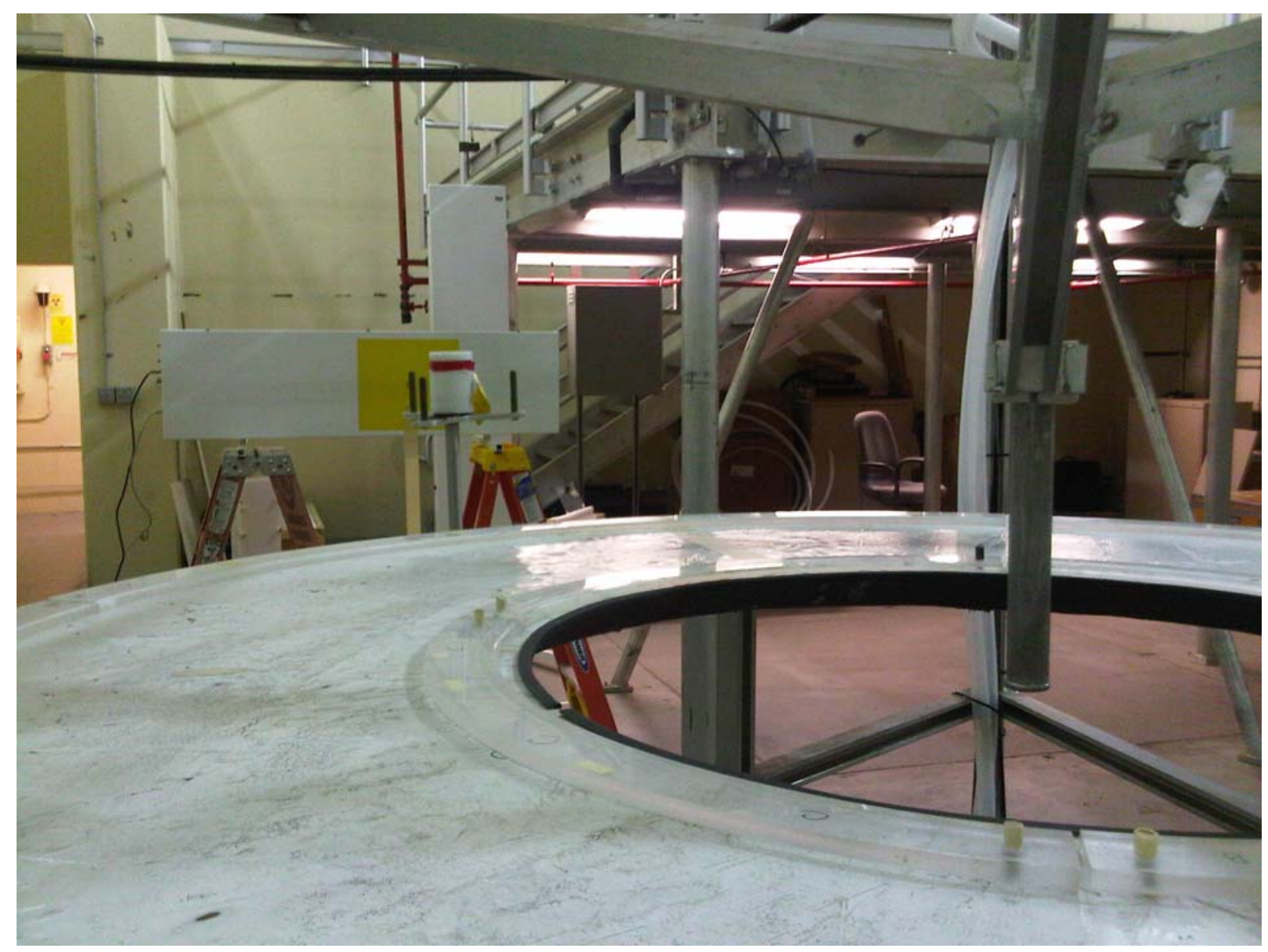

Figure 5.3: Small IAT detector positioned for gamma ray and neutron measurements. 


\section{Results and Data Analysis}

\subsection{Static Test of Large IAT System}

The data were collected with the IAT system software provided by the vendor. The data derived from the static tests were an average number of cps calculated over the ten-minute data acquisition time. The original IAT software settings were not altered for any of the tests. Backgrounds were acquired and subsequently subtracted from each test configuration to provide the net count rate. The uncertainty in the absolute values obtained was dominated by the uncertainty in the neutron source strengths. Table 6.1 summarizes the data obtained. It was noted that paddle 1 of the four paddles had a somewhat higher background count rate, but the net rate was consistent with the other detector paddles and was included in the analysis of the static data.

The efficiency measurements were made at both the front and the back of the detector with the moderated source at $2 \mathrm{~m}$ and perpendicular from the vertical and horizontal exterior of the housing. The default threshold of zero (equivalent to channel 15 used in later tests) was used for these measurements. The net efficiency was found to be $2.0 \pm 0.1 \mathrm{cps} / \mathrm{ng}$ of ${ }^{252} \mathrm{Cf}$ for both the front and back of the detector, as expected given the symmetry of the moderator around the detectors paddles. This value falls short of the specified value of $2.5 \mathrm{cps} / \mathrm{ng}$. Based on the previous measurements of the smaller IAT system, it was anticipated that this full-scale system would meet the requirement. The vendor stated that they had manufactured the new paddles using an engineered process rather than the previous hand process. In the conversion to the engineered process, they had inadvertently reduced the ${ }^{6} \mathrm{Li}$ doping in the $\mathrm{ZnS}$. They reportedly corrected this problem, and expected to recover $\sim 25 \%$ in efficiency for the next batch of paddles. The test results for this new paddle are discussed below. The vendor also thinks that they can improve the efficiency further with geometry changes.

Table 6.1. Neutron data from full scale IAT detector.

\begin{tabular}{|lcc|}
\hline \multicolumn{1}{|c}{ Configuration } & $\begin{array}{c}\text { Gross Sum of 4 } \\
\text { Detectors (cps) }\end{array}$ & Net cps/ng \\
\hline Efficiency: & & \\
Background & 3.37 & - \\
Source at 2 m from detector front & 80.22 & 1.98 \\
Source at 2 m from detector back & 81.26 & 2.01 \\
& & \\
\hline Angular Dependence: & & \\
Source at 30 degrees \& 2 m from detector front & 75.38 & 1.86 \\
Source at 60 degrees \& 2 m from detector front & 55.34 & 0.96 \\
Source at $~ 90$ degrees \& 2 m from detector front & 40.8 & \\
& & - \\
\hline 1.5" Polyethylene Reflector Added: & & 2.24 \\
Background & 3.13 & 1.33 \\
Source at 2 m from detector front & 90.15 & \\
Source at 2 m from detector back & 54.79 & \\
\hline
\end{tabular}

A series of measurements was made varying the angle of the source to the front panel. Figure 6.1 shows the angular dependence for the data given in Table 6.1. The detector response remained good and was consistent with the solid angle of the detector relative to the source. 


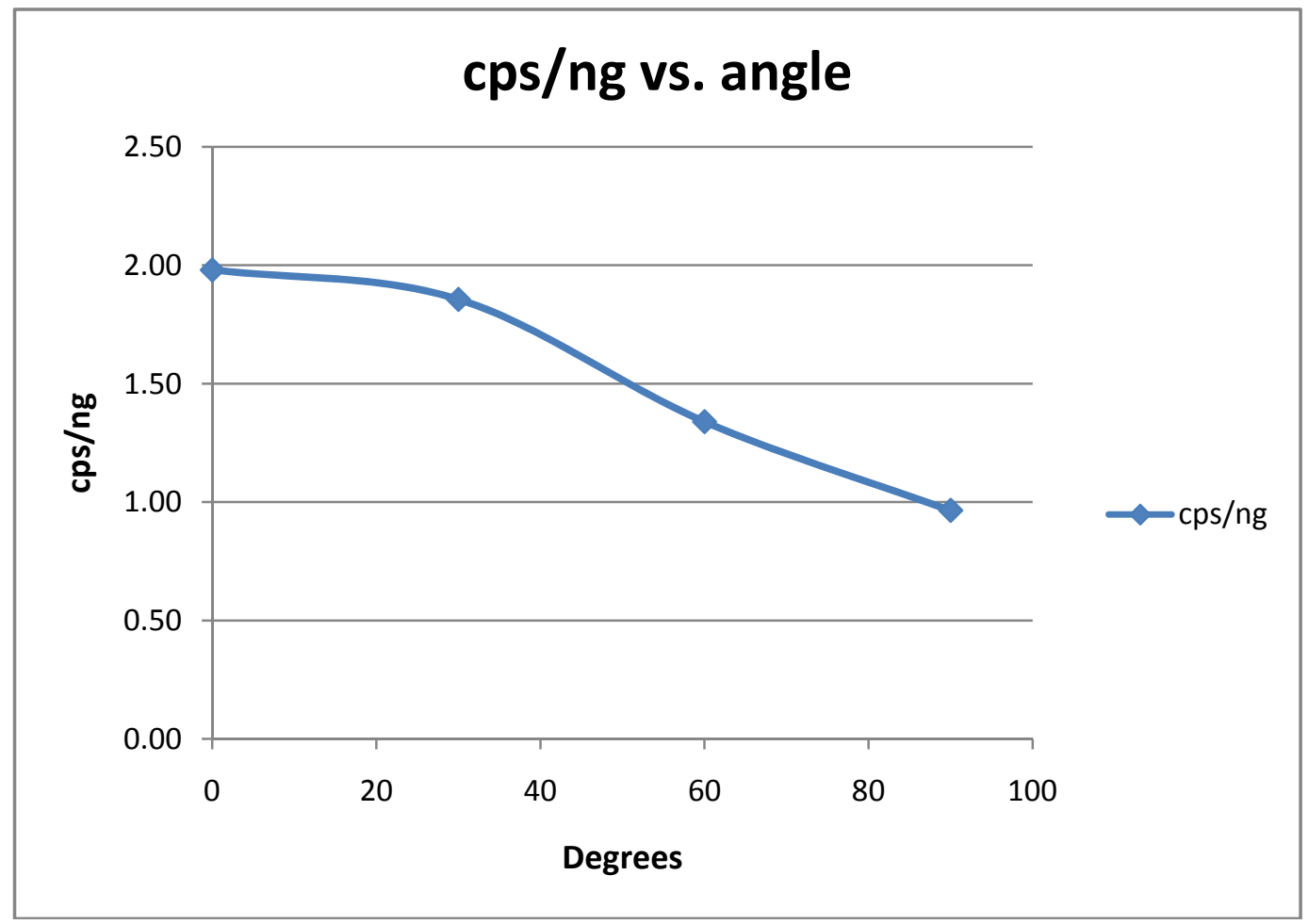

Figure 6.1. Detector response as a function of angle.

Measurements were also made with added polyethylene on the back of the detector unit. The data in Table 6.1 show that there was a $12.4 \%$ increase in neutron detection efficiency with this added $38 \mathrm{~mm}$ of polyethylene on the back of the detector, which acted as a reflector for neutrons. This indicated that the detector had an inadequate amount of reflector in the standard configuration.

\subsection{Static Test Of Enhanced Paddle For Large IAT System}

When IAT delivered the large system, the measurements showed that the efficiency of the four paddles in the system was not that expected from scaling calculations of the previous data taken on the small system, as discussed above. With this information, IAT revised their production of the detector paddles, and one new paddle was tested on February 23-24, 2010. One each of the new and old paddles was placed in a moderator box for testing, as seen in Figure 6.2 (with the neutron source in place for an efficiency measurement). Figure 6.3 shows the response of these two paddles to a neutron source.

Measurements showed that the new "enhanced" paddle did not perform significantly better in this moderator configuration than the old paddle. For example, the count rates from the two paddles for a neutron source at $2 \mathrm{~m}$ and a default threshold were 0.77 and $0.74 \mathrm{cps} / \mathrm{ng}$ for the new and old versions, respectively. 


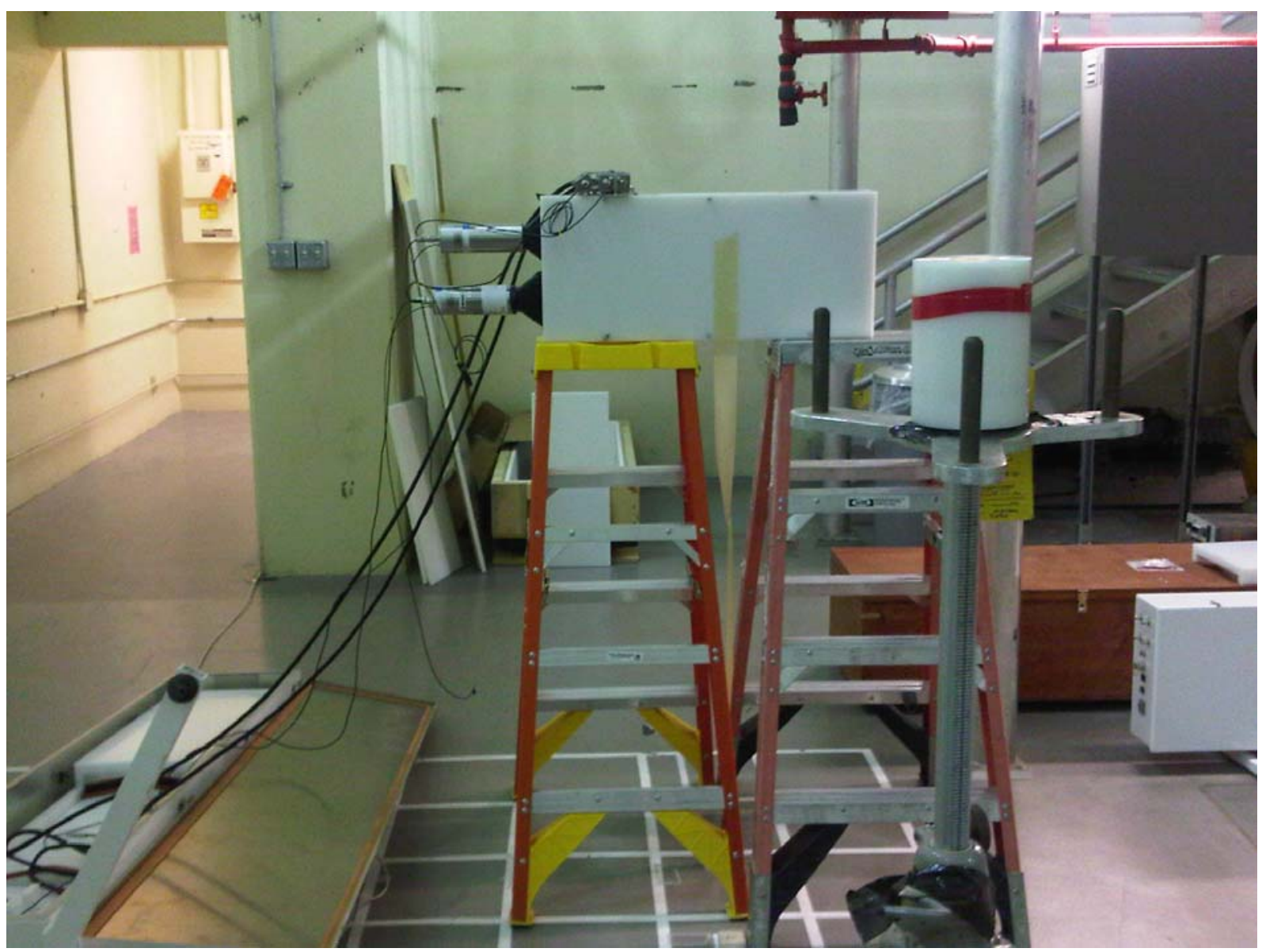

Figure 6.2. New and old paddles in a moderator box for testing.

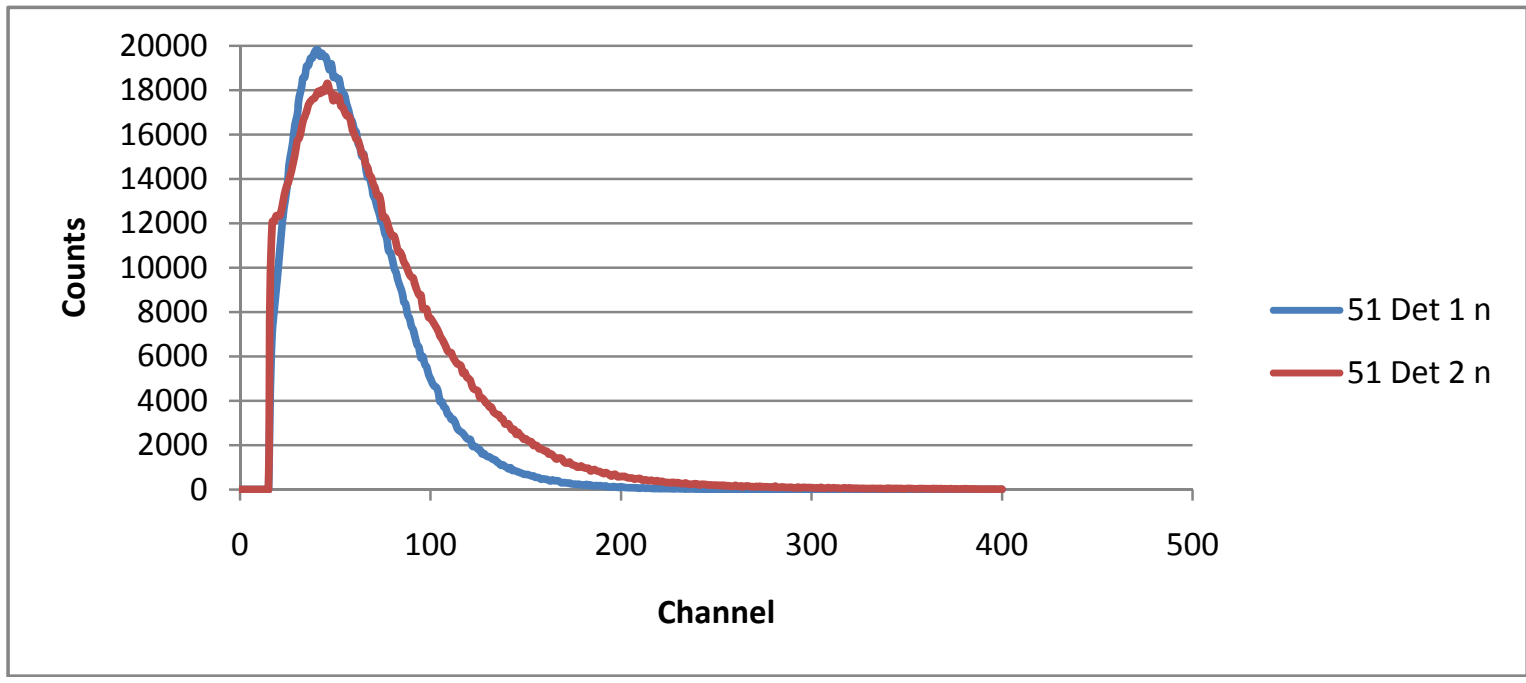

Figure 6.3. Response of new (Det 1) and old (Det 2) paddles to a neutron source. 


\subsection{Gamma Insensitivity Test Of The Large IAT System}

The detector's sensitivity to gamma rays was tested with a ${ }^{60} \mathrm{Co}$ source flooding the entire detector active area with a high-exposure-rate gamma field. During some of the tests a ${ }^{252} \mathrm{Cf}$ neutron source was also present to test that the neutron efficiency remains in the presence of gamma rays. Data were collected over five-minute intervals for four different scenarios (background, ${ }^{60} \mathrm{Co}$ source, ${ }^{60} \mathrm{Co}$ plus ${ }^{252} \mathrm{Cf}$, and only ${ }^{252} \mathrm{Cf}$ ).

Each of the four internal detector paddles provided separate data, and their data would normally be combined to obtain a composite count rate. Figure 6.4 shows pulse height spectra obtained when only a neutron source was present, and Figure 6.5 shows pulse height spectra obtained when a neutron source was present and the gamma exposure rate was $10 \mathrm{mR} / \mathrm{hr}$.

One of the detector paddles (Detector 1) produced significantly more (by a factor that varied from about 1.5 to 7 ) counts than the other three detectors did individually (Figure 6.5 best shows the difference in response). While the other three detectors show some variation, they behave much more similarly than Detector 1 . Apparently Detector 1 was malfunctioning, or its electronics were set different from the other detectors. Hence, the data from Detector 1 were not included in the analysis. Instead, the sum of the counts from the other three detectors was scaled to what would be expected if all four detectors were working similarly. For a final detector assembly, the vendor will need to ensure that all detectors have similar behavior for both neutron and gamma ray detection.

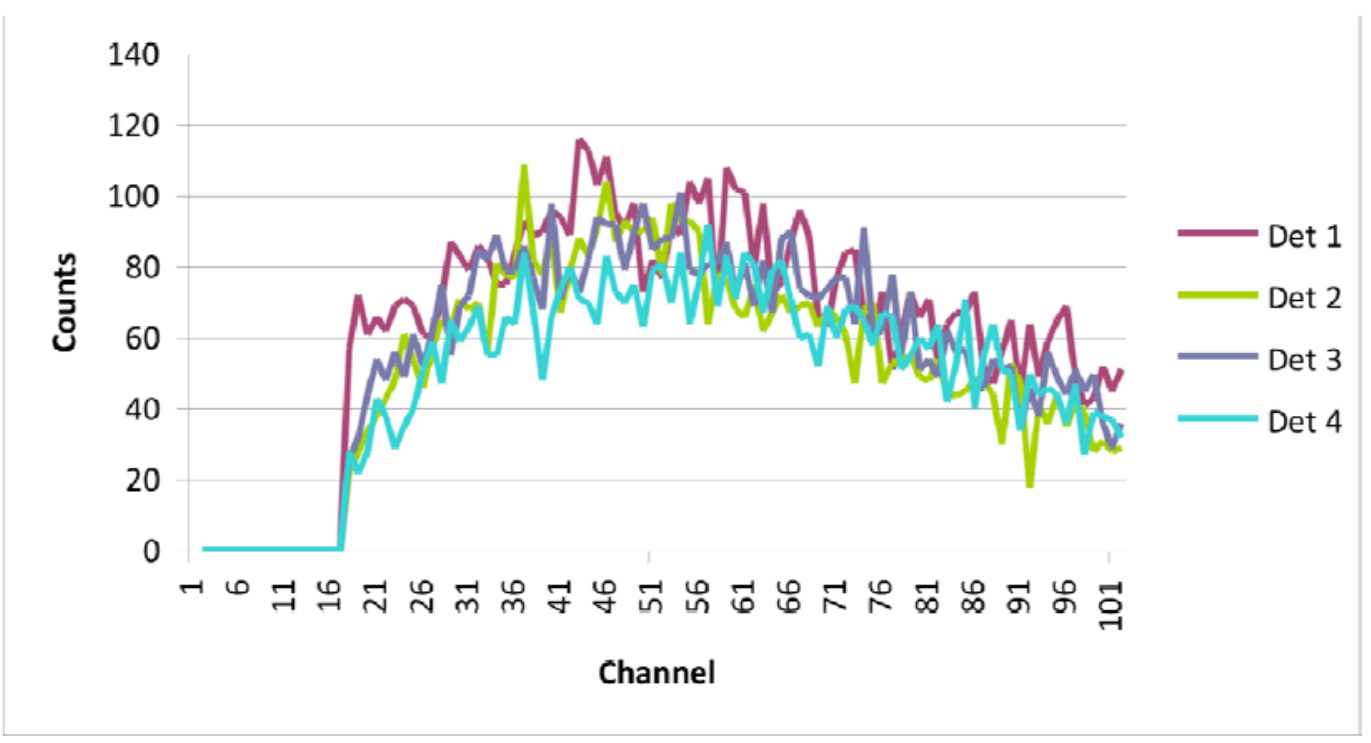

Figure 6.4: Pulse height spectra of the four individual detectors with only the neutron source. 


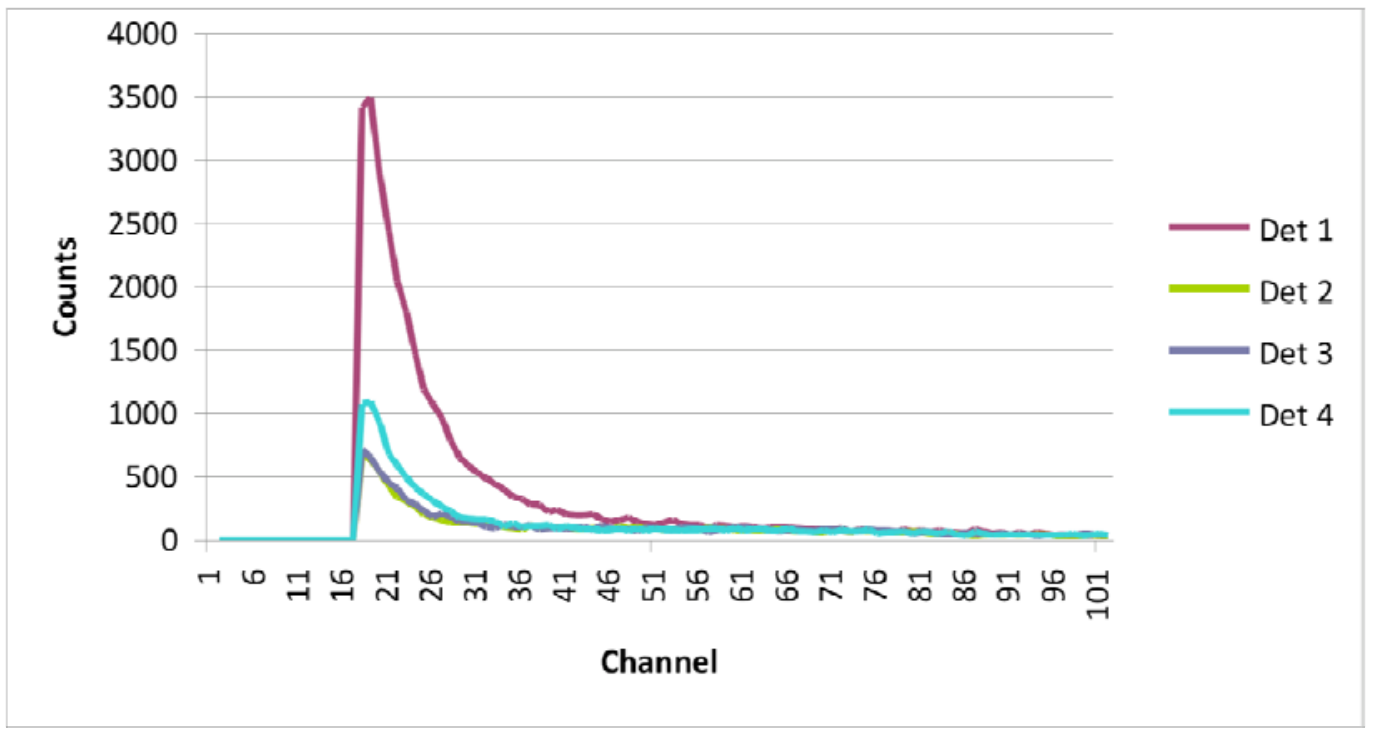

Figure 6.5: Pulse height spectra of the four individual detectors with the neutron source and at a gamma ray exposure rate of $10 \mathrm{mR} / \mathrm{hr}$.

Table 6.2 gives the adjusted neutron count rates recorded for gamma ray exposure rates ranging from 5 $\mathrm{mR} / \mathrm{hr}$ to $100 \mathrm{mR} / \mathrm{hr}$ with a default threshold of zero (equivalent to channel 15) for summing the measured spectra. The rates given are the "adjusted" net rates (with only the 3 better detector paddles and multiplying by $4 / 3$ ). Note that the ${ }^{60} \mathrm{Co}$ source produces significant false "neutron" counts, ranging from $11 \mathrm{cps}$ at $5 \mathrm{mR} / \mathrm{hr}$ to over $10000 \mathrm{cps}$ at $80 \mathrm{mR} / \mathrm{hr}$. The background detection rate was about 0.9 cps. The absolute neutron detection efficiency was $2.4 \mathrm{cps} / \mathrm{ng}{ }^{252} \mathrm{Cf}$, which was slightly higher than the rate measured with the detector outside and is a result of reflected of neutrons from the walls.

Table 6.2: "Neutron" counts recorded for various ${ }^{60} \mathrm{Co}$ exposure rates with a zero threshold.

\begin{tabular}{|c|c|c|c|c|}
\hline $\begin{array}{c}\text { Exposure } \\
\text { Rate } \\
(\mathrm{mR} / \mathrm{hr})\end{array}$ & $\begin{array}{l}\text { Net }{ }^{60} \text { Co only } \\
\text { (cps) }\end{array}$ & $\begin{array}{l}\text { Net }{ }^{252} \text { Cf only } \\
\text { (average cps) }\end{array}$ & $\begin{array}{c}\text { Net }{ }^{252} \text { Cf and }{ }^{60} \mathrm{Co} \\
\text { (cps) }\end{array}$ & $\begin{array}{c}\text { Net }\left({ }^{252} \mathrm{Cf} \&{ }_{(\mathrm{cps})}^{60} \mathrm{Co}\right) \operatorname{minus}{ }^{252} \mathrm{Cf} \\
\text { f }\end{array}$ \\
\hline 5 & 11 & 91 & 110 & 19 \\
\hline 10 & 66 & 91 & 157 & 66 \\
\hline 20 & 438 & 91 & 521 & 430 \\
\hline 40 & 2368 & 91 & 2416 & 2325 \\
\hline 60 & 6036 & 91 & 6198 & 6107 \\
\hline 80 & 10738 & 91 & 10413 & 10322 \\
\hline 100 & Not measured & 91 & 14274 & 14183 \\
\hline
\end{tabular}

Table 6.3 gives the adjusted neutron count rates recorded in the presence of various sources for the gamma exposure rates ranging from $5 \mathrm{mR} / \mathrm{hr}$ to $100 \mathrm{mR} / \mathrm{hr}$ with a threshold of channel 43 (in post analysis) for summing the measured spectra. This higher threshold reduces the sensitivity to gamma rays, but also reduces the neutron efficiency. This post-analysis threshold can be set as the default threshold in the system parameters when a final threshold is determined to meet all system requirements including the gamma insensitivity requirement. The background rate at this threshold was about $0.04 \mathrm{cps} / \mathrm{ng}$. The absolute neutron detection efficiency at this threshold was $2.1 \mathrm{cps} / \mathrm{ng}{ }^{252} \mathrm{Cf}$. 
Measured outside, this value would be somewhat smaller since the inside measurements include reflections from the walls.

Table 6.3: "Neutron" counts recorded for various ${ }^{60} \mathrm{Co}$ exposure rates with a threshold at channel 43.

\begin{tabular}{|c|c|c|c|c|}
\hline $\begin{array}{c}\text { Exposure } \\
\text { Rate } \\
(\mathrm{mR} / \mathrm{hr})\end{array}$ & $\begin{array}{l}\text { Net }{ }^{60} \mathrm{Co} \text { only } \\
(\mathrm{cps})\end{array}$ & $\begin{array}{l}\text { Net }{ }^{252} \text { Cf only } \\
\text { (average cps) }\end{array}$ & $\begin{array}{c}\text { Net }^{252} \mathrm{Cf} \text { and } \\
\text { (cps) }\end{array}$ & $\begin{array}{c}\text { Net }\left({ }^{252} \mathrm{Cf} \&{ }_{(\mathrm{cps})}^{60} \mathrm{Co}\right) \operatorname{minus}{ }^{252} \mathrm{Cf} \\
\end{array}$ \\
\hline 5 & 0.2 & 66 & 74 & 8 \\
\hline 10 & 1.3 & 66 & 67 & 1 \\
\hline 20 & 8.6 & 66 & 76 & 10 \\
\hline 40 & 51 & 66 & 111 & 45 \\
\hline 60 & 147 & 66 & 211 & 145 \\
\hline 80 & 286 & 66 & 335 & 269 \\
\hline 100 & Not measured & 66 & 471 & 405 \\
\hline
\end{tabular}

\section{${ }^{60}$ Co Gamma Flux Estimate}

The gamma ray intrinsic efficiencies can be calculated by developing an estimate of the gamma ray flux at the detector. The gamma ray flux at the detector was estimated from the measured exposure rate at the detector, two gamma rays per decay, and the gamma factor for ${ }^{60} \mathrm{Co}\left(13.2 \mathrm{R} \cdot \mathrm{cm}^{2} /(\mathrm{hr} \cdot \mathrm{mCi})\right)$. The detectors surface area was taken as the area of the polyethylene moderator ( $6403 \mathrm{~cm}^{2}$ or 12 " $\mathrm{x} 82.7$ "). The results are shown in Table 6.4.

Table 6.4: Estimated number of photons incident on the active area of the detector.

\begin{tabular}{|c|c|c|}
\hline $\begin{array}{c}\text { Exposure Rate } \\
(\mathbf{m R} / \mathbf{h r})\end{array}$ & $\begin{array}{c}\text { Detector to Source } \\
\text { Distance }(\mathbf{m})\end{array}$ & $\begin{array}{c}\text { Estimated Photons } \\
\text { on Detector (cps) }\end{array}$ \\
\hline 5 & 5.37 & $5.7 \times 10^{7}$ \\
\hline 10 & 3.80 & $1.1 \times 10^{8}$ \\
\hline 20 & 2.68 & $2.3 \times 10^{8}$ \\
\hline 40 & 1.90 & $4.6 \times 10^{8}$ \\
\hline 60 & 1.55 & $6.9 \times 10^{8}$ \\
\hline 80 & 1.34 & $9.2 \times 10^{8}$ \\
\hline 100 & 1.20 & $1.1 \times 10^{9}$ \\
\hline
\end{tabular}

\section{Gamma Insensitivity Measurement Results}

A value for the efficiencies and GARRn can be estimated from the calculated photon flux and the unscaled neutron efficiency. The neutron efficiency used to calculate GARRn for each gamma exposure was the absolute efficiency associated with each particular measurement. Thus, any geometrical effects are divided out of the results. The absolute neutron efficiency is the neutron count rate in $\mathrm{cps} / \mathrm{ng}{ }^{252} \mathrm{Cf}$ for a source at $2 \mathrm{~m}$ in a specified pig ( $6 \mathrm{~mm}$ of lead and $25 \mathrm{~mm}$ of polyethylene). The intrinsic gamma ray efficiency is the number of detected counts divided by the number of photons striking the detector surface area. The GARRn value is the detector event rate in the presence of both a neutron and gamma ray source divided by the detector event rate in the presence of only a neutron source. Table 6.4 shows the results for this IAT detector for two thresholds, one at channel zero (equivalent to channel 15) and the other at channel 43 (used in post-analysis).

For a threshold of zero, the IAT detector tested has intrinsic gamma ray efficiencies $\left(\epsilon_{\text {int }} \gamma \mathrm{n}\right)$ on the order of $10^{-7}$ for ${ }^{60} \mathrm{Co}$ exposure rates up to $10 \mathrm{mR} / \mathrm{hr}$ and thus meets the required value of $10^{-6}$ for an 
exposure rate of $10 \mathrm{mR} / \mathrm{hr}$. For a threshold at channel 43 , the detector has $\epsilon_{\text {int } \gamma \mathrm{n}}$ on the order of $10^{-8}$ for ${ }^{60} \mathrm{Co}$ exposure rates up to $20 \mathrm{mR} / \mathrm{hr}$.

The GARRn value for ${ }^{60} \mathrm{Co}$ at $10 \mathrm{mR} / \mathrm{hr}$ is 1.7 with the threshold at zero, outside the desired window $(0.9 \leq$ GARRn $\leq 1.1)$, and is 1.0 with a threshold at channel 43 (used in post-analysis), within the desired window. The GARRn values for exposure rates above $10 \mathrm{mR} / \mathrm{hr}$ are outside the window, indicating that there is an increase in count rate from gamma rays when the detector is exposed to high gamma exposures. These results indicate that the IAT detector may have adequate gamma ray insensitivity to allow use in fielded systems, but there is some loss of neutron efficiency in the presence of high gamma exposure rates. The system neutron efficiency will need to be increased to simultaneously meet all requirements.

Thus, at a threshold where GARRn is within the acceptable range, the absolute efficiency measured inside Building 318 is $2.1 \mathrm{cps} / \mathrm{ng}{ }^{252} \mathrm{Cf}$ (with no gamma-ray source present). The detector will require improved efficiency to simultaneously meet all the detection requirements, especially when measured outside. The vendor believes that the system will be improved in efficiency and will thus then meet all requirements.

Table 6.4: Estimates of absolute efficiency, GARRn and the intrinsic gamma ray rejection factor for the different gamma exposure rates for the large detector tested for two thresholds (T).

\begin{tabular}{|c|c|c|c|c|c|c|}
\hline $\begin{array}{c}\text { Exposure } \\
\text { Rate } \\
(\mathrm{mR} / \mathrm{hr})\end{array}$ & $\begin{array}{c}\text { Absolute } \\
\text { Neutron } \\
\text { Efficiency } \\
\epsilon_{\mathbf{n}} \\
T=0\end{array}$ & $\begin{array}{c}\text { Intrinsic } \\
\text { Gamma Ray } \\
\text { Efficiency } \\
\epsilon_{\text {int gn }} \\
\mathbf{T}=0\end{array}$ & $\begin{array}{c}\text { GARRn } \\
\epsilon_{\text {abs } \gamma \mathbf{n}} / \boldsymbol{\epsilon}_{\mathrm{n}} \\
\mathbf{T}=\mathbf{0}\end{array}$ & $\begin{array}{c}\text { Absolute } \\
\text { Neutron } \\
\text { Efficiency } \\
\epsilon_{\mathrm{n}} \\
T=43\end{array}$ & $\begin{array}{c}\text { Intrinsic } \\
\text { Gamma Ray } \\
\text { Efficiency } \\
\boldsymbol{\epsilon}_{\text {int gn }} \\
\mathbf{T}=\mathbf{4 3}\end{array}$ & $\begin{array}{c}\text { GARRn } \\
\epsilon_{\text {abs rn }} / \epsilon_{n} \\
T=43\end{array}$ \\
\hline 0 & 2.42 & - & 1 & 1.7 & - & 1 \\
\hline 5 & 2.9 & $2.0 \times 10^{-7}$ & 1.20 & 2.0 & $4.2 \times 10^{-9}$ & 1.10 \\
\hline 10 & 4.2 & $5.8 \times 10^{-7}$ & 1.71 & 1.8 & $1.2 \times 10^{-8}$ & 1.03 \\
\hline 20 & 13.8 & $1.9 \times 10^{-6}$ & 5.69 & 2.0 & $3.7 \times 10^{-8}$ & 1.14 \\
\hline 40 & 64.1 & $5.2 \times 10^{-6}$ & 26.4 & 3.0 & $1.1 \times 10^{-7}$ & 1.67 \\
\hline 60 & 164.4 & $8.8 \times 10^{-6}$ & 67.6 & 5.6 & $2.1 \times 10^{-7}$ & 3.12 \\
\hline 80 & 276.2 & $1.2 \times 10^{-5}$ & 113.6 & 8.9 & $3.1 \times 10^{-7}$ & 5.02 \\
\hline 100 & 378.6 & - & 155.7 & 12.5 & - & 7.06 \\
\hline
\end{tabular}

\subsection{Gamma Insensitivity Test Of The Upgraded Small IAT System}

The sensitivity to gamma rays of the upgraded small IAT system $(0.25 \mathrm{~m}$ by $0.25 \mathrm{~m}$ moderator $)$ was tested with a ${ }^{60} \mathrm{Co}$ source flooding the entire detector (Figure 5.3). The response of the two detectors in this system to gamma ray exposure rates of $10 \mathrm{mR} / \mathrm{h}$ and $40 \mathrm{mR} / \mathrm{h}$ is shown in Figure 6.6. The measurements of this system with the gamma ray source indicated that a threshold at channel 43 (used in post-analysis) would produce a GARRn value of 1.05 at an exposure rate of $10 \mathrm{mR} / \mathrm{h}$

With the threshold at channel 43 (for an acceptable GARRn), the absolute efficiency of the sum of the two detectors was found to be $0.84 \mathrm{cps} / \mathrm{ng}$. This efficiency can be compared to the previous test of the earlier small system (Lintereur 2009) of $0.50 \mathrm{cps} / \mathrm{ng}$ (with a threshold that produced an acceptable GARRn). Thus, the improved design of this upgraded detector gave a $68 \%$ improvement in absolute efficiency. The caveat on this result is that the earlier measurements were performed outside while these new measurement were performed inside. Nonetheless, this performance enhancement is 
significant and if a large system is built with this improved design, its performance should be substantially improved over the current large system design.

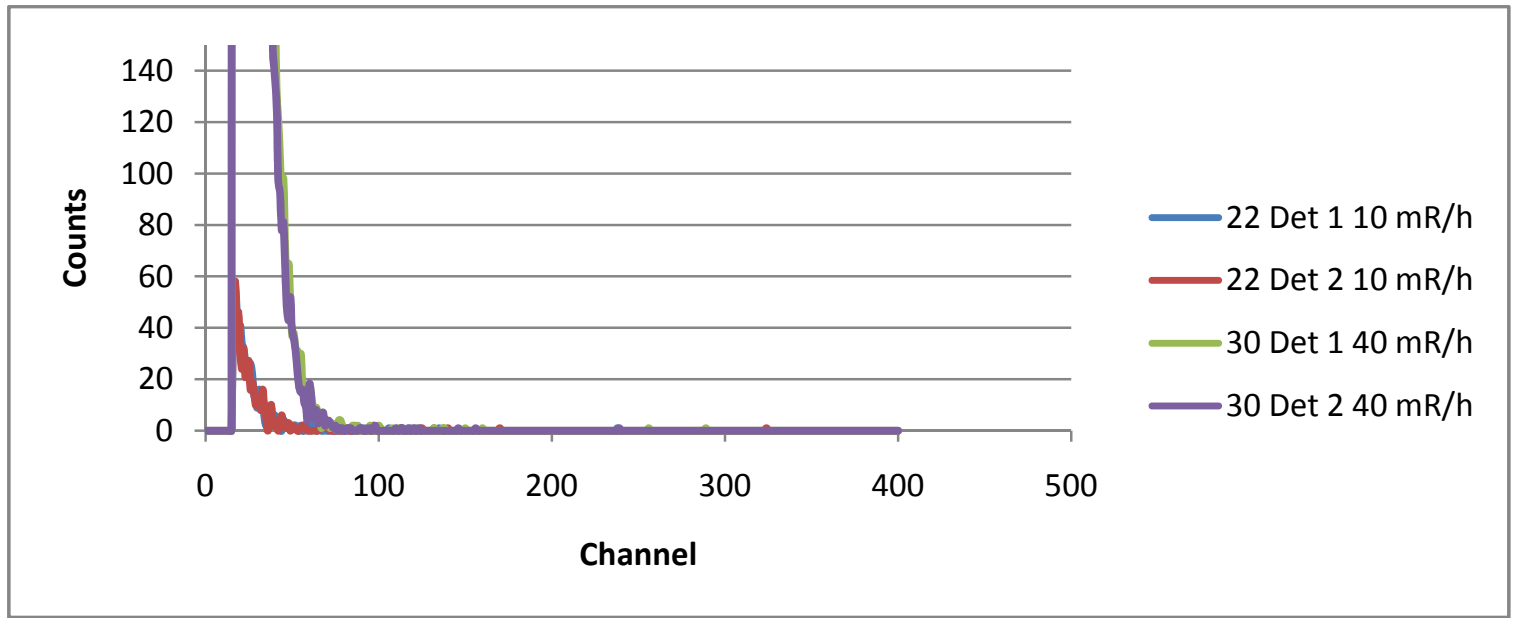

Figure 6.6: Pulse height spectra from the two detector paddles in the small IAT system in response to gamma ray exposure rates of $10 \mathrm{mR} / \mathrm{hr}$ and $40 \mathrm{mR} / \mathrm{h}$. 


\section{Conclusions}

The large IAT prototype detection system has been tested and compared to ${ }^{3} \mathrm{He}$ as a possible alternative neutron detection technology. The IAT detector uses plastic fibers that are coated with ${ }^{6} \mathrm{Li} / \mathrm{ZnS}(\mathrm{Ag})$ to detect neutrons. Discrimination between neutrons and gamma rays is based on pulse shape.

The tests were conducted on a large IAT detector with four "paddles," each of which is $0.127 \mathrm{~m}$ by $0.635 \mathrm{~m}(5$ " $\mathrm{x} 25$ ") with one phototube at the end. Results suggest that neutron detection efficiency comparable to existing ${ }^{3} \mathrm{He}$ detectors will be obtained with the improvements planned by the vendor that consist of changes to the fiber coating method, addition of reflector material, and changes to the configuration of the fibers.

Test results indicate that adequate intrinsic gamma ray efficiency (gamma ray rejection) is obtained for all gamma exposure rates measured by including a post-analysis threshold that reduces the neutron detection efficiency. The GARRn value at a ${ }^{60} \mathrm{Co}$ exposure rate of $10 \mathrm{mR} / \mathrm{hr}$ is within the desired range when the post-analysis threshold is included, indicating that there is some miscounting of neutrons in the presence of large gamma exposure rates. Additional efficiency is needed from the system in order to simultaneously meet all the detection requirements.

Testing of an enhanced paddle did not show the expected improvement in performance. However, tests on a new design of the detector with moderator inserted between layers showed a significant improvement in efficiency while meeting the gamma ray insensitivity requirement. If this design is scaled to the full sized neutron detection system, the performance should meet the requirements for neutron sensitivity and gamma ray rejection. 


\section{References}

ANSI. 2004. American National Standard for Evaluation and Performance of Radiation Detection Portal Monitors for Use in Homeland Security. Technical Report. ANSI 42.35, American Nuclear Standards Institute, Washington, D.C.

Kouzes RT, J Ely, and E Siciliano. 2007. "Neutron Alarm Algorithms for Deployed RPMs." PIET43741-TM-663, PNNL-17101, Pacific Northwest National Laboratory, Richland, Washington.

Kouzes, RT, JH Ely, PE Keller, RJ McConn, and ER Siciliano. 2008. "Passive Neutron Detection for Interdiction of Nuclear Material at Borders." Nuclear Instruments and Methods in Physics Research Section A: Accelerators, Spectrometers, Detectors and Associated Equipment 584(2-3): 383-400.

Kouzes RT, Ely J, Lintereur A, Stephens D. 2009. Neutron Detector Gamma Insensitivity Criteria. PNNL -18903, Pacific Northwest National Laboratory, Richland, Washington.

Kouzes, RT, 2009. “The ${ }^{3}$ He Supply Problem," Pacific Northwest National Laboratory Report PNNL18388.

Lintereur, AT, JR Ely, RT Kouzes, LE Erikson, DC Stromswold, 2009. "Coated Fiber Neutron Detector Test," PNNL-18919 (September 2009).

Stromswold D, J Ely, R Kouzes, J Schweppe. 2003. Specifications for Radiation Portal Monitor Systems Revision 6.7. PIET-43741-TM-017, Pacific Northwest National Laboratory, Richland, Washington.

Van Ginhoven, RM, RT Kouzes, DL Stephens, 2009. “Alternative Neutron Detector Technologies for Homeland Security,” Pacific Northwest National Laboratory Report PNNL-18471. 


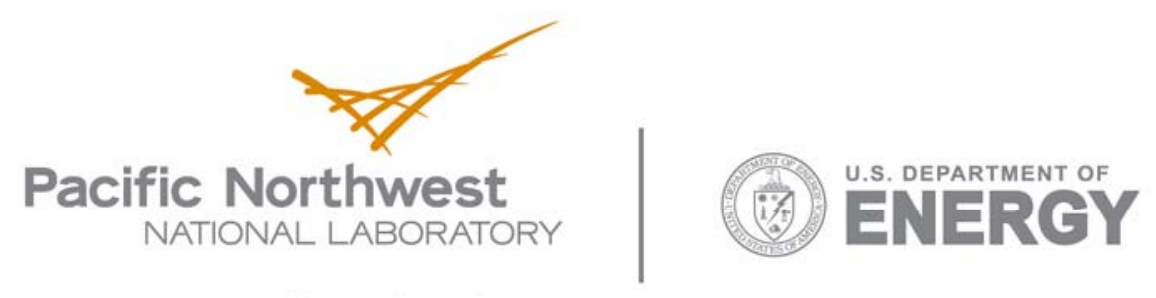

902 Battelle Boulevard

P.O. Box 999

Richland, WA 99352

1-888-375-PNNL (7665)

www.pnl.gov 